\title{
Article \\ Genomic Characteristics and Comparative Genomics Analysis of Two Chinese Corynespora cassiicola Strains Causing Corynespora Leaf Fall (CLF) Disease
}

\author{
Boxun $\mathrm{Li}^{1,2}$, Yang Yang ${ }^{1,2}$, Jimiao Cai ${ }^{1,2}$, Xianbao Liu ${ }^{1,2}$, Tao Shi ${ }^{1,2}$, Chaoping $\mathrm{Li}^{1,2}$, Yipeng Chen ${ }^{1,2}$, Pan $\mathrm{Xu}^{3}$ \\ and Guixiu Huang $1,2, *$ \\ 1 Environment and Plant Protection Institute, Chinese Academy of Tropical Agricultural Sciences, \\ 4 Xueyuan Road, Haikou 571101, China; diyningxiang@126.com (B.L.); yangyang@catas.cn (Y.Y.); \\ cjmiao1231@163.com (J.C.); liuxianbao2013@126.com (X.L.); shitaofly2008@163.com (T.S.); \\ lichaoping2008@163.com (C.L.); cypkiller@163.com (Y.C.) \\ 2 College of Grassland Agriculture Science and Technology, Lanzhou University, 222 Tianshui South Road, \\ Lanzhou 730000, China \\ 3 Key Laboratory of Integrated Pest Management on Tropical Grops, Ministry of Agriculture and Rural Affairs, \\ Beijing 100020, China; digers_xup900104@163.com \\ * Correspondence: hgxiu@catas.cn
}

check for updates

Citation: Li, B.; Yang, Y.; Cai, J.; Liu, X.; Shi, T.; Li, C.; Chen, Y.; Xu, P.; Huang, G. Genomic Characteristics and Comparative Genomics Analysis of Two Chinese Corynespora cassiicola Strains Causing Corynespora Leaf Fall (CLF) Disease. J. Fungi 2021, 7, 485. https://doi.org/10.3390/ jof7060485

Academic Editor: Willem Melchers

Received: 27 May 2021

Accepted: 8 June 2021

Published: 16 June 2021

Publisher's Note: MDPI stays neutra with regard to jurisdictional claims in published maps and institutional affiliations.

Copyright: (C) 2021 by the authors Licensee MDPI, Basel, Switzerland This article is an open access article distributed under the terms and conditions of the Creative Commons Attribution (CC BY) license (https:// creativecommons.org/licenses/by/ $4.0 /)$
Abstract: Rubber tree Corynespora leaf fall (CLF) disease, caused by the fungus Corynespora cassiicola, is one of the most damaging diseases in rubber tree plantations in Asia and Africa, and this disease also threatens rubber nurseries and young rubber plantations in China. C. cassiicola isolates display high genetic diversity, and virulence profiles vary significantly depending on cultivar. Although one phytotoxin (cassicolin) has been identified, it cannot fully explain the diversity in pathogenicity between $C$. cassiicola species, and some virulent $C$. cassiicola strains do not contain the cassiicolin gene. In the present study, we report high-quality gapless genome sequences, obtained using short-read sequencing and single-molecule long-read sequencing, of two Chinese C. cassiicola virulent strains. Comparative genomics of gene families in these two stains and a virulent CPP strain from the Philippines showed that all three strains experienced different selective pressures, and metabolismrelated gene families vary between the strains. Secreted protein analysis indicated that the quantities of secreted cell wall-degrading enzymes were correlated with pathogenesis, and the most aggressive CCP strain (cassiicolin toxin type 1) encoded $27.34 \%$ and $39.74 \%$ more secreted carbohydrate-active enzymes (CAZymes) than Chinese strains YN49 and CC01, respectively, both of which can only infect rubber tree saplings. The results of antiSMASH analysis showed that all three strains encode $\sim 60$ secondary metabolite biosynthesis gene clusters (SM BGCs). Phylogenomic and domain structure analyses of core synthesis genes, together with synteny analysis of polyketide synthase (PKS) and non-ribosomal peptide synthetase (NRPS) gene clusters, revealed diversity in the distribution of SM BGCs between strains, as well as SM polymorphisms, which may play an important role in pathogenic progress. The results expand our understanding of the $C$. cassiicola genome. Further comparative genomic analysis indicates that secreted CAZymes and SMs may influence pathogenicity in rubber tree plantations. The findings facilitate future exploration of the molecular pathogenic mechanism of C. cassiicola.

Keywords: comparative genomics; Corynespora cassiicola; pathogenicity; Corynespora leaf fall disease; rubber tree; secondary metabolites

\section{Introduction}

The fungus Corynespora cassiicola (Berk. and Curt) C. T. Wei, belonging to the Ascomycota phylum, Dothideomycetes class, and Pleosporales order, is responsible for diseases in a wide range of plants, including rubber tree, tomato, cucumber, soybean, cotton, and various others [1]. This fungus has also been isolated from sponges, nematodes, and 
rare human infections [2-4]. C. cassiicola was once considered a weak pathogen of rubber trees (Hevea brasiliensis, Muell. Arg.), until Corynespora leaf fall (CLF) disease was first reported in Sierra Leone, which devastated more than 4000 ha of the highly susceptible rubber cultivar RRIC103 in the 1980s [5,6]. Since then, CFL disease has rapidly spread through most rubber-producing countries in Asia and Africa, causing severe sporadic epidemics and damaging losses to natural rubber yields, making it among the most important cryptogamic diseases of rubber plantations [7].

CLF disease is characterised by the development of necrotic lesions on leaves, with frequent blackening of the veins, resulting in a typical 'fish-bone' or 'railway track' appearance. Both immature and mature leaves are affected, leading to massive defoliation and consequent growth delay and yield losses [8]. In China, CLF disease was first detected in 2006 in rubber nurseries and young rubber plantations in the Yunnan and Hainan provinces [9]. The rubber tree is native to the Amazon basin, but historically it has been widely cropped in tropical regions within equatorial zones (between $10^{\circ} \mathrm{N}$ and $10^{\circ} \mathrm{S}$ ) [10]. With increasing demand for natural rubber, rubber plantations expanded rapidly through the 20th century in China [11], and China is now the world's third largest rubber plantation region, with a planting area of 1.18 million ha (ANRPC). Unlike other rubber-producing countries, most rubber plantations in China are scattered between $18^{\circ} \mathrm{N}$ and $24^{\circ} \mathrm{N}$, and some rubber plantations in the Yunnan province have expanded into marginal growing environments as far north as $24^{\circ} \mathrm{N}$ and at high elevations exceeding $1300 \mathrm{~m}$ [12]. Differences in geographical environment and climate variation can lead to genetic variation between fungal strains. C. cassiicola strains sequenced in this study were separately isolated from rubber plantations in Hekou, the Yunnan province (strain YN49), and Yangjiang, the Guangdong province (strain CC01). The straight-line distance between the two places is more than 800 kilometres, and they have very different ecological environment and weather conditions.

Cassiicolin, a small 27 amino acid secreted glycoprotein with six cysteines engaged in three disulphide bonds, is the only characterised C. cassiicola effector to date [13]. Six different cassiicolin isoforms (Cas1-6) have been described from different $C$. cassiicola isolates sampled from various hosts and geographical origins, and some lack the cassiicolinencoding gene (Cas0 isolates) [14]. According to one study [14], Cas1 is the major rubber tree-specialised isolate in the Philippines, while Cas3, 4 and 5 are the most abundant in Malaysia, and Cas5, Cas0 and Cas2 predominate in China, and Cas2 types are only found in cucumber and soybean in other countries [15]. These results indicate that $C$. cassiicola strains evolved independently due to geographical factors.

Interestingly, Cas0 isolates, which have no cassiicolin-encoding gene, can also cause CFL in rubber trees and other plants, such as tomato, pepper and papaya $[14,16]$. This indicates that a variety of pathogenic factors remain to be identified in C. cassiicola. The cell wall, which comprises a matrix of pectin, hemicellulose, lignin and structural proteins, is an important barrier that protects plants from pathogen attack [17]. In rubber trees, a thick cuticle and wax layer improves resistance to phytopathogenic fungi [18]. To overcome this barrier, phytopathogenic fungi produce cell wall-degrading enzymes (CWDEs) that degrade cellulose, xylan, pectin and cell wall polymers [19]. Lopez et al. (2018) analysed proteins secreted from C. cassiicola and found that this fungus secretes a variety kinds of degradatory enzymes, including proteases, carbohydrate-active enzymes (CAZymes) and lipases [16]. Meanwhile, Liu et al. (2011) found that C. cassiicola secretes CWDEs as pathogenic factors, including cutinase, as well as cytomembrane- and cell inclusion-degrading enzymes [20]. However, whether and how secreted proteins affect the pathogenicity of $C$. cassiicola toward rubber trees remains unclear.

C. cassiicola $\mathrm{CCP}$, a highly virulent strain collected from diseased rubber trees in the Philippines, is the only C. cassiicola strain for which the whole genome has been sequenced, assembled and annotated [16,21]. Lopez et al. (2018) identified 63 secondary metabolite biosynthesis gene clusters (SM BGCs) in CCP, far more than in other phytopathogenic fungi $(\sim 40)$ [16]. Filamentous fungi produce a diverse array of SMs that function as toxins, antibi- 
otics and pigments [22]. In phytopathogenic fungi, a variety of SMs are produced during interactions with plants, and used as weapons to invade host plants [23]. SM biosynthetic genes in filamentous fungi are typically organised into contiguous gene clusters in the genome, and clustered near chemical backbone synthesis genes, such as non-ribosomal peptide synthases (NRPSs), polyketide synthases (PKSs) and terpene synthases [24]. In contrast to obligate biotrophic fungi, necrotrophic and hemibiotrophic fungi often contain many SM BGCs [23]. However, synthetic products of SM gene clusters in C. cassiicola and their roles in pathogenesis remain unclear. SM gene clusters vary between $C$. cassiicola strains, and their relevance to pathogenicity requires further study.

In the present study, we determined gapless genome sequences of two highly virulent C. cassiicola strains that cause CFL disease in rubber trees in China. This is the first genome reported for a Chinese CFL disease-causing strain. In order to analyse pathogenesisrelated genes and pathways, we compared Chinese strains and a virulent reference isolate $\mathrm{CCP}$ genome. The results showed that all three strains evolved under different selective pressures, and possess different secreted CAZymes and SM gene cluster compositions. This indicates that secreted CAZymes and SMs may influence pathogenicity in fungi affecting rubber trees, and may also partially explain the high variability in the pathogenicity of C. cassiicola.

\section{Materials and Methods}

\subsection{Fungal Growth Conditions and DNA Preparation}

C. cassiicola YN49 (CGMCC 3.20259) and CC01 (CGMCC 3.20258) strains were separately isolated from rubber plantations in Hekou, Yunnan province, and Yangjiang, Guangdong province. Both strains were maintained in our laboratory. Fungi were grown on potato dextrose agar medium and incubated at $28^{\circ} \mathrm{C}$ for 10 days. Mycelia were harvested and DNA was extracted from grounded mycelia using a genomic DNA kit (Qiagen, New York, NY, USA). Agarose gel electrophoresis, a NanoDrop 1000 spectrophotometer (Thermo, Bedford, MA, USA) and a Qubit fluorimeter (Thermo, Bedford, MA, USA) were used to analyse the integrity, quality, and concentration of DNA, respectively. Genomic DNA was further purified for sequencing (Oxford Nanopore Technology, Oxford, UK) using a BluePippin DNA size selection system (Sage Science, Beverly, MA, USA).

\subsection{Pathogenicity Tests}

Rubber tree cultivar Reyan7-33-97, one of the main rubber varieties in China, was selected to analysis pathogenicity of $C$. cassiicola YN49 and CC01 according to protocol of Déon's with modifications [14]. The C. cassiicola isolates were cultivated on PDA medium at $28^{\circ} \mathrm{C}$ and conidia were collected and resuspended in sterile water at a concentration of 10,000 conidia $\mathrm{mL}^{-1}$. Three drops of each conidial suspension $(20 \mu \mathrm{L})$ were applied to the abaxial surface of 1 detached rubber tree leaflet at developmental stage $C$ (brownish to limp green) and leaflets were maintained in a moist environment at $28^{\circ} \mathrm{C}$ for $24 \mathrm{~h}$ in the dark and then under alternate light (photoperiod $12 \mathrm{~h} / 12 \mathrm{~h}$ ).

\subsection{Detection and Sequencing of the Cassiicolin-Encoding Genes}

Detection of the cassiicolin gene was conducted by PCR on genomic DNA from C. cassiicola isolates YN49 and CC01. Primers and PCR reaction conditions of Déon's were used for cassiicolin gene detection [14]. PCR product of cassiicolin genes was sequenced by BGI (Shenzhen, China). Maximum likelihood trees generated using amino acid sequences of $\mathrm{A}$ and $\mathrm{KS}$ domains were constructed using the method described previously by Déon et al. (2014) with MEGA version 6.0.

\subsection{Genome Sequencing and Assembly}

After repairing DNA damage, an SQK-LSK108 ligation kit (Oxford Nanopore Technology, UK) was used to construct a library, and a Qubit fluorimeter was used to assess the quality of the library. Single-molecule real-time sequencing of long reads was conducted on 
a GridION X5 platform (Oxford Nanopore Technology, UK). After filtering the sequencing adapters and low-quality sequences, clean data $(\mathrm{YN} 49,5.1 \mathrm{~Gb}$ clean reads, $115 \times$ sequencing depth; $\mathrm{CC} 01,10.5 \mathrm{~Gb}$ clean reads, $228 \times$ sequencing depth) were obtained and assembled using CANU (version 1.3) [25] with default parameters. In addition, a separate paired-end (PE) DNA library was sequenced using an Illumina HiSeq4000 platform (Illumina, San Diego, CA, USA). The sequencing data (filtered reads $=2.99 \mathrm{~Gb}$, sequencing depth $=90 \times$ ) were used to further improve the assembly using bwa mem (version 0.7.12-r1039) and two runs of Pilon (version 1.22) with continuous iteration correction [26]. The integrity of assembly was evaluated using BUSCO (benchmarking universal single-copy orthologs) version 3.0.1 (https:/ / busco.ezlab.org/ accessed on 13 October 2020) [27].

\subsection{Gene Prediction and Annotation}

A combination of Augustus and Glimmer was used for de novo prediction of proteincoding genes by constructing models. GeneWise [28] was then used to predict proteincoding genes via homology analysis with known protein sequences from related species (C. cassiicola, Cercospora canescens, Bipolaris maydis, Pyricularia oryzae, Fusarium oxysporum and Pseudocercospora fijiensis). EVidenceModeler (EVM) (http:/ / evidencemodeler.github.io/ accessed on 13 October 2020) was subsequently used to compute weighted consensus gene structure annotations. We obtained the final gene sets after removing genes with transposable elements using TransposonPSI (http: / / transposonpsi.sourceforge.net/ accessed on 13 October 2020). Functional annotations for all predicted gene models were made using multiple databases, including Swiss-Prot, NR, KEGG and COG, and BlastP, with E-values $\leq 1.0 \times 10^{-5}$.

\subsection{Orthologous Gene Family, Phylogenetic, and Whole-Genome Synteny Analyses}

OrthoMCL [29] was used for analysis of orthologous gene families (E-values $\leq 1.0 \times 10^{-5}$ ) by comparing proteins from C. cassiicola YN49 and CC01 with those of the following 10 phytopathogenic fungi: C. cassiicola CCP (GCA_003016335.1), B. maydis (GCA_000338975.1), C. zeae-maydis (2761,201,826 JGI), Parastagonospora nodorum (GCA_002267025.1), Exserohilum turcica (GCA_000359705.1), Pyrenophora tritici-repentis (GCA_000149985.1), P. oryzae (GCA_000002495.2), Aspergillus flavus (GCA_009017415.1), F. graminearum (GCA_000240135.3) and Botrytis cinerea (GCA_000143535.4). Phylogenetic relationships between C. cassiicola YN49, CC01 with the other 10 phytopathogenic fungi were analysed using single-copy orthologous gene groups. Gblocks (with default parameters) were used to remove divergence and ambiguously aligned blocks from the alignment to obtain a better CDS file. A maximum likelihood tree was constructed using RaxML [30] with the GTRGAMMA model and 100 bootstrap replicates to infer phylogenetic relationships. Synteny blocks between C. cassiicola YN49, CC01 and CCP were identified and represented by minimap2 (version 2.17) with the cx asm5 parameter [31].

\subsection{Gene Family Expansion Analysis}

Using the OrthoMCL gene family results, CAFE (computational analysis of gene family evolution, version 4.0.1) [32] was employed to detect gene family expansion and contraction (using divergence time instead of branch length).

\subsection{Positive Selection}

To perform positive selection, we obtained a new gene set of orthologous gene pairs using the genomes of the 12 phytopathogenic fungi mentioned before. Using BLAST (version 2.2.30) with an E-value cut-off $\leq 1.0 \times 10^{-5}$, we identified orthologous gene pairs with reciprocal best hits among the 12 species. We estimated the $\mathrm{dN} / \mathrm{dS}$ ratio $(\omega)$ using PAML version 4.9e [33] with the coding sequence alignments above to determine the selection pressure on corresponding gene pairs. Genes with positively selected sites were detected using branch-site models (model $=2$ and NSsite $=2$ ). For the null hypothesis we used the parameters fix_omega $=1$ and omega $=1$, but for the alternative hypothesis 
we used fix_omega $=0$ and omega $=1.5$. We used a false discovery rate (FDR)-corrected likelihood ratio test (LRT) with an adjusted LRT $p$-value cut-off $\leq 0.05$ to identify positively selected sites of genes.

\subsection{Annotation of Specific Gene Categories}

The following five different methods were used to identify repetitive sequences: RepeatProteinMasker (version 1.36), RepeatMasker (version 4.0.7) [34], TRF, RepeatModeler (http:/ / repeatmasker.org/RepeatModeler/ accessed on 13 October 2020), and Ltrfinder [35]. CAZymes were predicted in YN49, CC01 and CCp strain genomes by performing a BLASTP search (E-values $\leq 1.0 \times 10^{-5}$ ) against the Carbohydrate-Active EnZYmes (CAZy) database (http:/ / www.cazy.org/ accessed on 13 October 2020) with predicted protein sequences as queries [36].

Lipases, proteases and the secretome were predicted according to the procedure described previously by Lopez and colleagues for Corynespora cassiicola [16]. Hmmsearch (HMMER 3.1b1; http:/ / hmmer.org/ accessed on 13 October 2020) was used with predicted protein sequences as queries to search against the Lipase Engineering Database (version 3) with an E-value inclusion threshold set at 0.01 [37]. Proteases were predicted in YN49, CC01 and CCp strain genomes by performing a BLASTP search (E-values $\leq 1.0 \times 10^{-5}$ ) against the MEROPS blast database (version 9.12) with predicted protein sequences as queries [38]. SignalP (http://www.cbs.dtu.dk/services/SignalP/ accessed on 13 October 2020) was used to predict signal peptides and cleavage sites of predicted proteins. Proteins with a signal P D-score $=\mathrm{Y}$ were scanned for transmembrane spanning regions using TMHMM (version 2.0; http: / / www.cbs.dtu.dk/services/TMHMM/ accessed on 13 October 2020) and all proteins with 0 TMs or $1 \mathrm{TM}$, if located in the predicted N-terminal signal peptide, were retained. Proteins potentially secreted through endoplasmic reticulum (ER)/Golgiindependent pathways were not taken into account in this study.

\subsection{Secondary Metabolite Gene Cluster Analysis}

Genes encoding putative polyketide synthases (PKSs), non-ribosomal peptide synthases (NRPSs), PKS-NRPS hybrids, terpene synthases (TSs), and their modules were identified by searching the antiSMASH database (fungal version; https:/ / fungismash. secondarymetabolites.org/ accessed on 13 October 2020) with default settings [39]. Genes putatively involved in secondary metabolism were also identified with antiSMASH. Maximum likelihood trees generated using amino acid sequences of $\mathrm{A}$ and $\mathrm{KS}$, and domains were constructed using the method described previously by Yang et al. (2019) with MEGA version 6.0 employing the Wheland and Goldman (WAG) mode [40]. Then, iTOL (v5) was used to annotate phylogenetic trees (https://itol.embl.de/index.shtml accessed on 13 October 2020).

\section{Results}

3.1. C. cassiicola Cas5 and Cas2 Isolates from China Differ in Virulence toward Rubber Tree Leaves

C. cassiicola YN49 and CC01 strains were separately isolated from rubber plantations in Hekou, the Yunnan province, and Yangjiang, the Guangdong province. Based on the sequence of the cassicolin-encoding gene, the YN49 strain belongs to Cas5 isolates and CC01 belongs to Cas2 isolates (Figure S1, Supplementary Materials File S7). YN49 and CC01 mycelia grown on PDA was fluffy and grey (Figure 1), similar to the CCP strain [16]. YN49 produced different pigments on PDA compared with other strains, and the PDA medium turned light orange as the mycelia aged (Figure 1). After 5 days of conidia inoculation, both YN49 and CC01 caused necrotic spots and typical darkening of the veins on the leaves of Hevea brasiliensis clone Reyan7-33-97, one of the main rubber tree cultivars in China. Compared with CC01, YN49 was more pathogenic toward Reyan7-33-97 (Figure 1). 

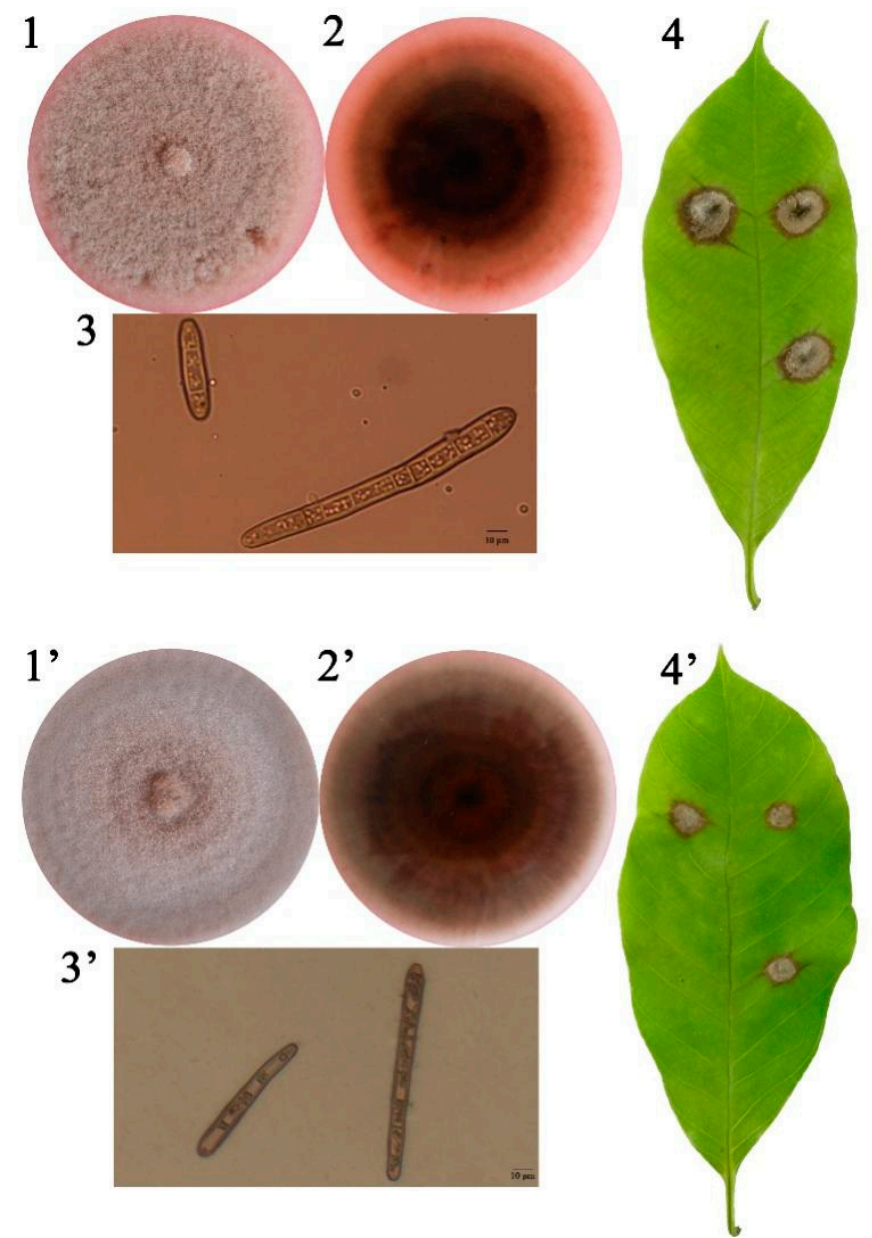

Figure 1. Symptoms of disease caused by Corynespora cassiicola YN49 and CC01 strains in Hevea brasiliensis clone Reyan7-33-97. The (1) and (1'): mycelium colony on PDA medium (front); (2) and $\left(2^{\prime}\right)$ : mycelium colony on PDA medium (back); (3) and ( $\left.3^{\prime}\right)$ : optical microscopy view of conidia in water; $(4)$ and $\left(4^{\prime}\right)$ : CLF symptoms on rubber tree clone Reyan7-33-97.

\subsection{General Genome Features and Annotation}

Single-molecule real-time sequencing of long reads was conducted on a GridION X5 platform, and the genome of YN49 was sequenced with $115 \times$ coverage, while the genome of CC01 was sequenced with $228 \times$ coverage. CANU was used for de novo assembly of the sequencing data with Pilon-based continuous iteration correction using Illumina HiSeq4000 sequencing data, which generated 32 contigs with an N50 length of $2.51 \mathrm{Mb}$ for the YN49 genome, and 33 contigs with an N50 length of $2.56 \mathrm{Mb}$ for YN49. The genome size of YN49 $(45.1 \mathrm{Mb})$ and CC01 $(47.1 \mathrm{Mb})$ is slightly larger than that of HGCC $(42.7 \mathrm{Mb}), \mathrm{CCP}(44.8 \mathrm{Mb})$ and UM591 $(41.4 \mathrm{Mb})$. The GC content of YN49 $(51.09 \%)$ and CC01 $(50.96 \%)$ is lower than that of HGCC $(51.78 \%)$, CCP $(51.89 \%)$ and UM591 (52.47\%; Table 1). The completeness of the genome assembly was assessed using BUSCO, which showed that $96.9 \%$ and $97.5 \%$ of the gene groups were correct assembled for the YN49 and CC01 scaffolds, respectively (Supplementary Materials File S1: Table S1). The YN49 genome contains 388 noncoding RNAs (ncRNAs) comprising 152 ribosomal RNAs (rRNAs), 44 small nuclear RNAs (snRNAs) and 192 transfer RNAs (tRNAs), while the CC01 genome contains fewer ncRNAs (338) comprising 79 rRNAs, 45 snRNAs and 214 tRNAs (Supplementary Materials File S1: Table S2). Furthermore, 8.18\% of the YN49 genome and $9.18 \%$ of the CC01 genome are repetitive based on de novo and referencebased repeat analysis results (Supplementary Materials File S1: Table S3). A total of 14,504 protein-coding genes were predicted in the YN49 genome, for which 13,312 (91.78\%) have 
at least one type of annotation from Cluster of Orthologous Groups of proteins (COG; $28.10 \%$ of genes), Gene Ontology (GO; $47.28 \%$ ), Kyoto Encyclopedia of Genes and Genomes (KEGG; 16.91\%), Non-Redundant Protein (NR; 91.71\%) or Swiss-Prot (59.11\%) databases. Additionally, 14,224 (82.61\%) of 17,219 total predicted protein-coding genes have at least one type of annotation (COG $24.87 \%$, GO $41.54 \%$, KEGG $14.82 \%$, NR $82.53 \%$, Swiss-Prot $51.30 \%$; Supplementary Materials File S1: Table S4).

Table 1. Genome characteristics and assembly features of C. cassiicola isolates YN49, CC01, HGCC, CCP and UM591.

\begin{tabular}{cccccc}
\hline Features & YN49 & CC01 & HGCC & CCP & UM591 \\
\hline Total genome size $(\mathrm{Mb})$ & 45.1 & 47.1 & 42.7 & 44.8 & 41.4 \\
Genome coverage & $115 \times$ & $228 \times$ & $184 \times$ & $123 \times$ & $118 \times$ \\
G + C content $(\%)$ & 51.09 & 50.96 & 51.78 & 51.89 & 52.47 \\
Number of contigs & 32 & 33 & 1032 & 644 & 1941 \\
Contig N50 (bp) & $2,523,863$ & $2,573,660$ & $/$ & 211,447 & 44,332 \\
Protein-coding genes & 14,504 & 17,219 & 14,631 & 17,167 & 14,744 \\
\hline
\end{tabular}

3.3. Analysis of Orthologues and Phylogenetic Relationships between C. cassiicola YN49 and CC01 and Other Fungi

We clustered the annotated genes of C. cassiicola YN49 and CC01, and the other 10 phytopathogenic fungi, into gene families, including 3,388 single-copy genes, which were used for phylogenetic tree construction. A maximum likelihood phylogenetic tree was generated by the RaxML method, based on the GTRGAMMA model (Figure 2). The results revealed that $C$. cassiicola $\mathrm{YN} 49$ and CC01 are evolutionarily closely related to C. cassiicola $\mathrm{CCP}$, a fungus isolated in the Philippines that causes CLF disease in rubber trees.
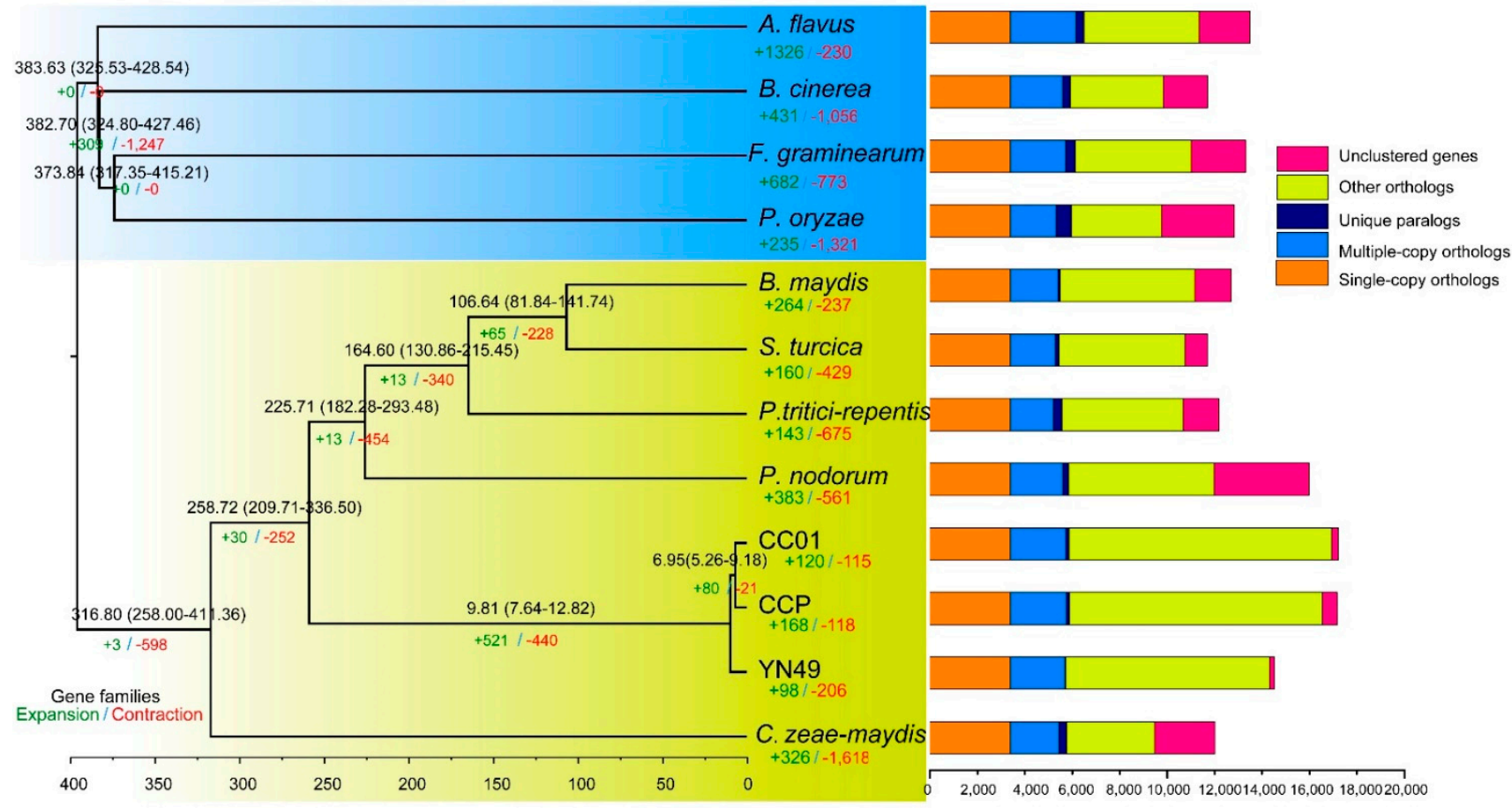

Figure 2. Phylogenetic relationships between C. cassiicola YN49 and CC01 strains and 10 other phytopathogenic fungi. Eurotiomycetes and Leotiomycetes fungi are indicated by a blue background, and yellow indicates Dothideomycetes fungi. Divergence times are labelled blue, gene family expansion and contraction are enumerated below the species names in green and red, respectively, and gene categories are shown on the right. 


\subsection{Gene Family Expansion and Contraction, and Positive Selection of Genes}

The expansion and contraction of gene families is thought to be important in adaptive phenotypic diversification [41]. For plant pathogenetic fungi, continuous coevolution of host plants gives rise to constant selective pressure for the preservation of expanded gene families relevant to virulence and host-based nutrient usage [42]. Based on sequence homology, we identified 98 (432 genes), 120 (479 genes) and 168 (734 genes) gene families showing expansion in YN49, CC01 and CCP genomes, respectively (Figure 2 and Supplementary Materials File S2: Table S4). We also identified 206 (212 genes), 115 (178 genes) and 118 (131 genes) gene families showing contraction in YN49, CC01 and CCP genomes, respectively (Figure 2 and Supplementary Materials File S2: Table S5). KEGG pathway enrichment analysis of expanded and contracted gene families indicated that most of these gene families are associated with primary and secondary metabolism pathways, such as amino acid, fatty acid, terpenoid and aflatoxin metabolism (Figure 3 and Figure S2; Supplementary Materials File S2: Tables S1 and S2). In addition to the expanded and contracted gene families, genes showing positive selection commonly contribute to adaptive phenotypic evolution and adaptation. Herein, 61, 49 and 24 genes were identified as positively selected genes in YN49, CC01 and CCP genomes, respectively (Supplementary Materials File S2: Table S6). KEGG (metabolic pathway) enrichment analysis of these positively selected genes revealed that some KEGG pathways that were significantly enriched were related to carbon metabolism and amino acid metabolism (Figure 4 and Supplementary Materials File S2: Table S3).

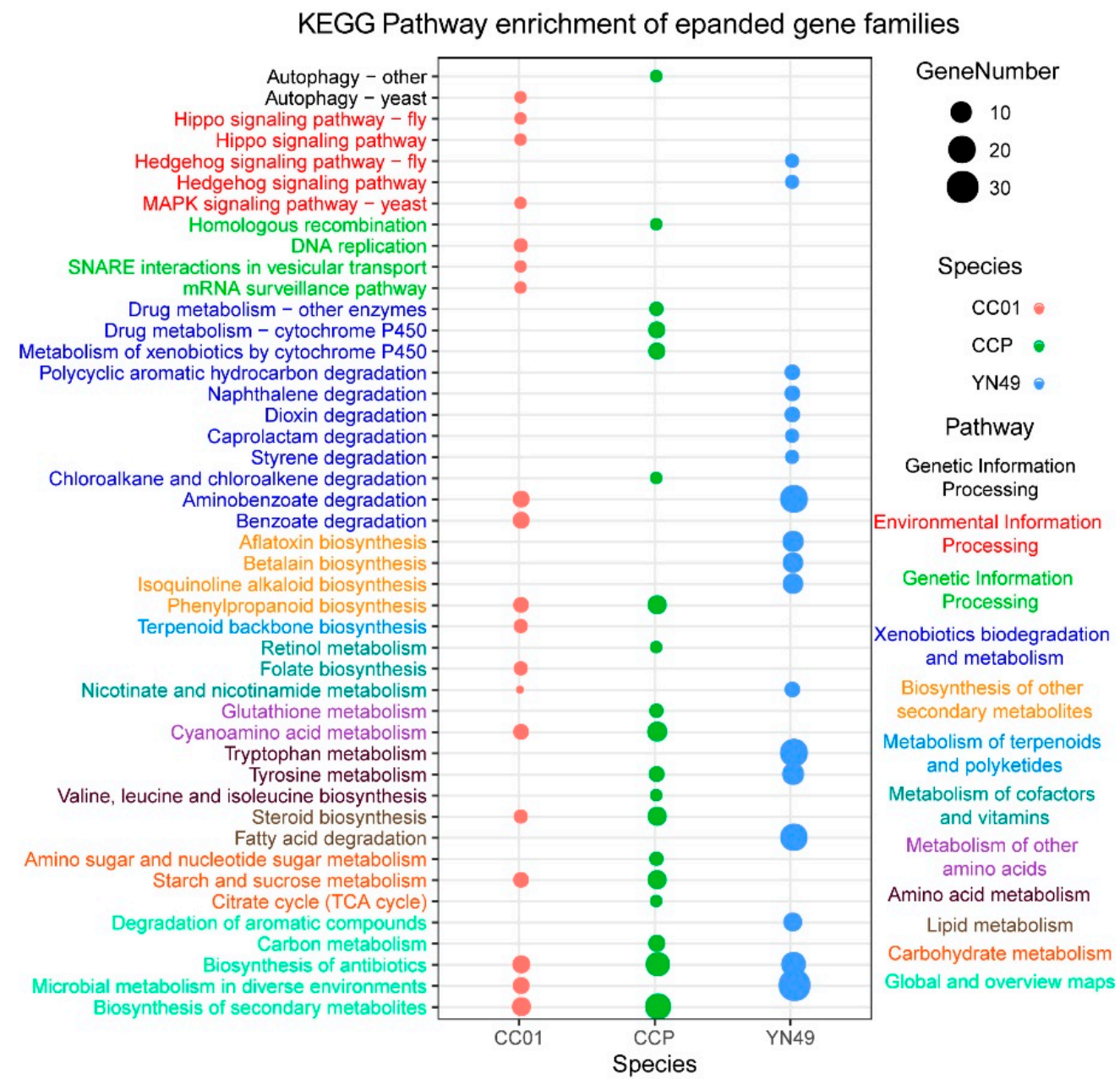

Figure 3. KEGG distribution of expanded gene families in C. cassiicola YN49, CC01 and CCP strains. 


\section{KEGG Pathway (Metabolism) enrichment of positive selection genes}

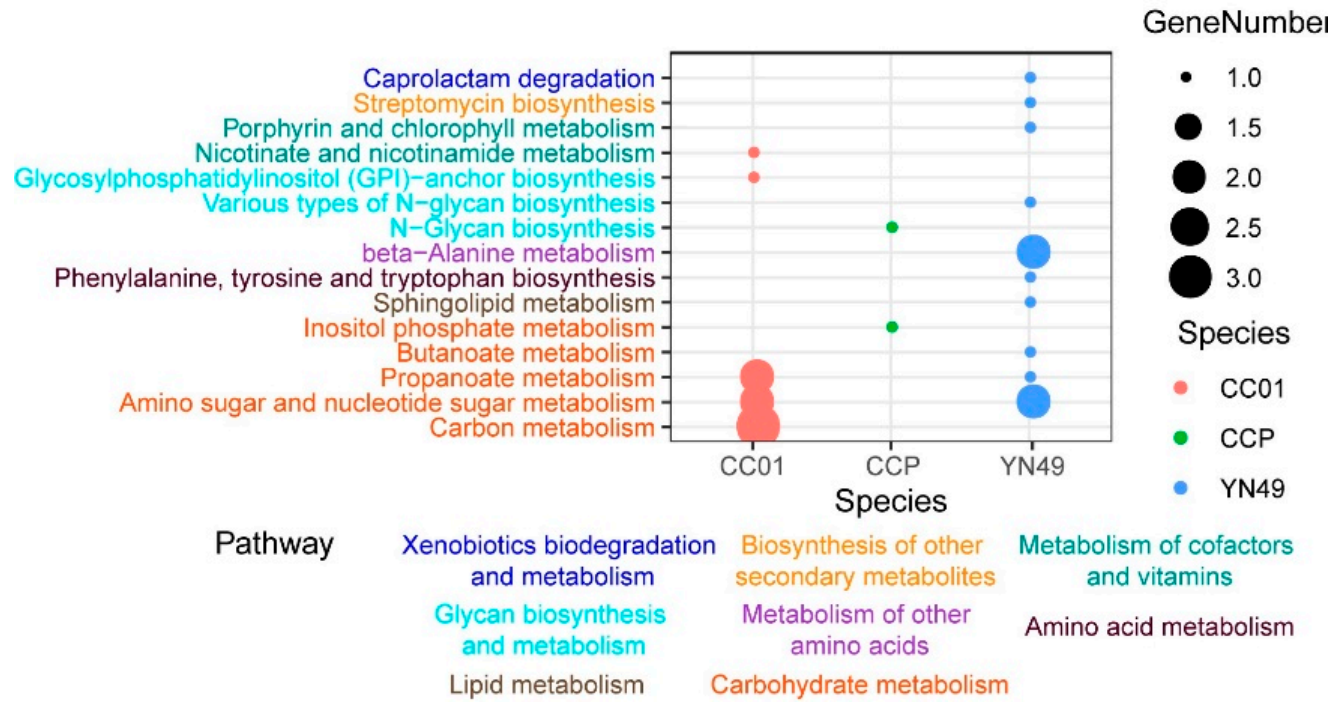

Figure 4. KEGG distribution (metabolic pathways) of positively selected genes in C. cassiicola YN49, CC01 and CCP strains.

\subsection{Whole-Genome Synteny Comparisons between C. cassiicola YN49, CC01 and CCP}

Phylogenomic analysis revealed that $C$. cassiicola YN49 and CC01 are evolutionarily closely related to $C$. cassiicola CCP. We therefore performed a synteny comparison between these three strains. The resulting synteny dot-plot displays macrosynteny between the three genomes, and high levels of sequence homology with each other; 19 contigs of YN49, 23 contigs of $\mathrm{CC} 01$ and 15 contigs of CCP have conserved syntenic blocks (Figure 5).

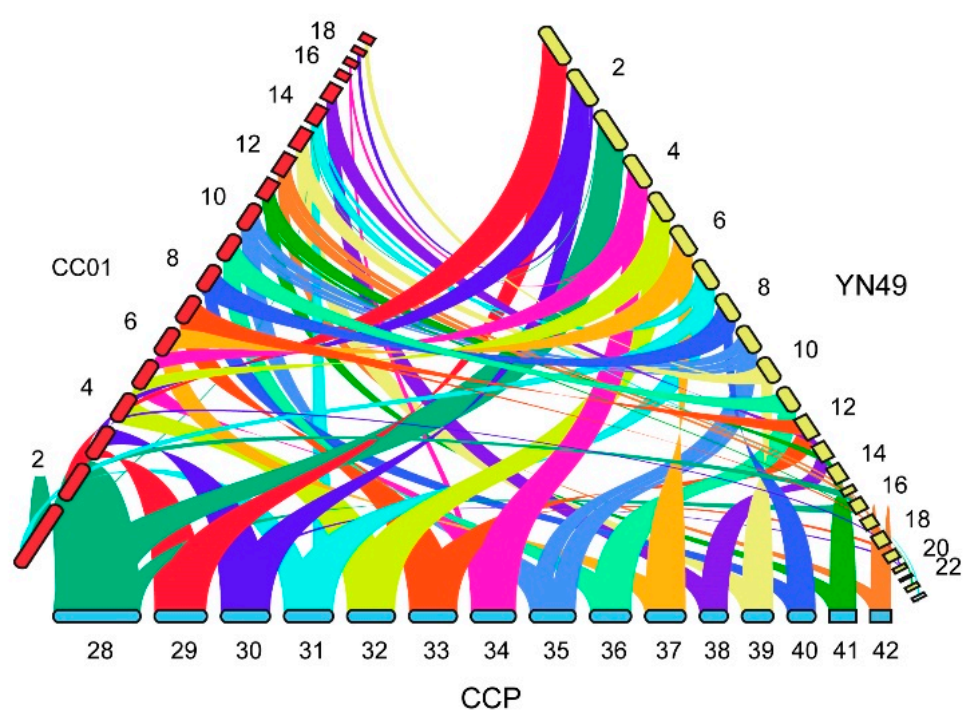

Figure 5. Synteny analysis of C. cassiicola YN49, CC01 and CCP strains. Phylogenomic analysis revealed that $C$. cassiicola YN49 and CC01 are evolutionarily closely related to C. cassiicola CCP. Therefore, we performed synteny comparison between these three species. The resulting synteny dot-plot shows macrosynteny between the three genomes, and high levels of sequence homology between strains. There are 19 contigs in YN49, 23 contigs in CC01 and 15 contigs in CCP with conserved syntenic blocks. 


\subsection{Secretome and Putative Pathogenicity Genes}

The secretome of a plant pathogenetic fungus includes extracellular secreted proteins that are deployed to the host-pathogen interface during infection, including important virulence factors such as effector proteins for the manipulation of host cell dynamics and cell wall-degrading enzymes [43]. A secretome prediction pipeline for C. cassiicola [16] was implemented to predict the secretomes of C. cassiicola YN49, CC01 and CCP. A total of 1563 secreted proteins in the YN49 genome, 1474 in the CC01 genome, and 1534 in the CCP genome were predicted, accounting for $10.78 \%, 8.56 \%$ and $8.93 \%$ of their proteomes, respectively (Figure 6). To be a successful phytopathogen, C. cassiicola encodes an array of hydrolytic enzymes, including CAZymes $(\mathrm{YN} 49=417 ; \mathrm{CC} 01=380 ; \mathrm{CCP}=531)$, proteases $(\mathrm{YN} 49=136 ; \mathrm{CC} 01=111 ; \mathrm{CCP}=124)$, and lipases $(\mathrm{YN} 49=204 ; \mathrm{CC} 01=180 ; \mathrm{CCP}=113)$ (Supplementary Materials File S3: Tables S1-S3). BLAST searching against the pathogenhost interactions (PHI) database [44] identified 5102, 5297 and 5239 putative pathogenicity genes in YN49, CC01 and CCP genomes, respectively (Figure 6 and Supplementary Materials File S4: Tables S1-S3). CAZymes and proteases are crucial for the degradation of the host plant cells, and to establish colonisation, while lipases also play an important role during the establishment of virulence [45]. The overlap of different secreted gene categories with genes relevant to fungal pathogenicity indicated that a large portion of secreted CAZymes $(\mathrm{YN} 49=263,63.07 \%$; CC01 $=243,63.95 \%$; $\mathrm{CCP}=346,65.16 \%)$, proteases $(\mathrm{YN} 49=83,61.29 \% ; \mathrm{CC} 01=71,63.96 \% ; \mathrm{CCP}=70,56.45 \%)$, and lipases $(\mathrm{YN} 49=65,31.86 \%$; $\mathrm{CC} 01=54,30.00 \%$; $\mathrm{CCP}=62,54.87 \%$ ) were relevant to pathogenicity (Figure 6 ).
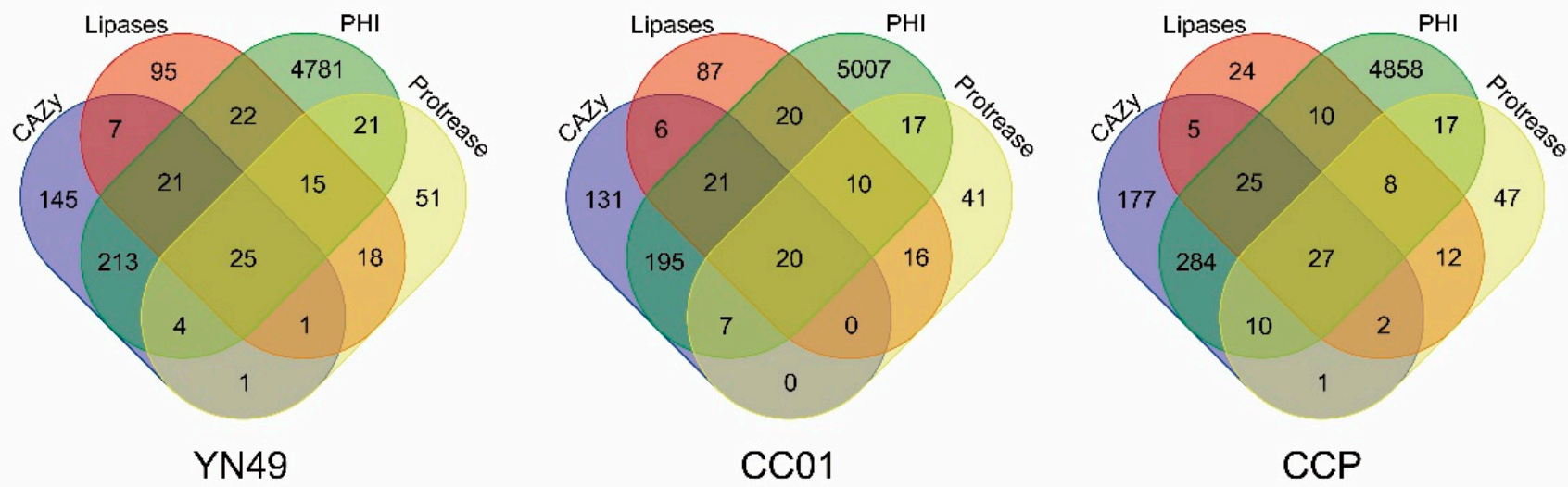

Figure 6. Venn diagram showing the overlap of different secreted gene categories with genes relevant to fungal pathogenicity.

\subsection{Carbohydrate-Active Enzymes}

Secreted carbohydrate degradation is an important component of fungal pathogenicity and virulence. Based on catalytic activity, CAZymes were further classified into auxiliary activities (AAs), carbohydrate esterases (CEs), glycoside hydrolases (GHs), glycosyl transferases (GTs), and polysaccharide lyases (PLs) [36]. We examined the CAZymes of C. cassiicola YN49, CC01 and CCP. Using the common CAZy annotation pipeline for the genomic analysis of fungi, we identified 417 putative secreted CAZymes falling into 83 CAZyme families in YN49, 380 falling into 79 families in CC01, and 531 falling into 101 families in CCP (Supplementary Materials File S3: Tables S1-S3). To overcome the barrier of the plant cell wall, phytopathogenic fungi produce enzymes that degrade cellulose, pectin and cutin, and that are capable of degrading cell wall polymers [19]. CAZymes involved in plant cell wall degradation, such as cellulose, hemicellulose pectin and cutin degradation, are listed in Table 2, according to classification by Chang [46] and Kubicek [19]. The results indicate that CCP possesses 223 secreted plant cell wall degradation-related CAZymes, $14.95 \%$ more than YN49 (194) and 21.19\% more than CC01 (184). 
Table 2. CAZymes involved in plant cell wall degradation.

\begin{tabular}{|c|c|c|c|c|}
\hline Substrates & Family & YN49 & CC01 & CСP \\
\hline \multirow{8}{*}{ Cellulose } & AA9 & 25 & 28 & 27 \\
\hline & GH1 & 2 & 1 & 3 \\
\hline & GH12 & 2 & 2 & 2 \\
\hline & GH3 & 13 & 12 & 13 \\
\hline & GH45 & 1 & 2 & 2 \\
\hline & GH5 & 31 & 27 & 37 \\
\hline & GH6 & 3 & 2 & 2 \\
\hline & GH7 & 5 & 5 & 5 \\
\hline \multirow{15}{*}{ Hemicellulose } & CE1 & 8 & 8 & 9 \\
\hline & GH10 & 3 & 4 & 4 \\
\hline & GH11 & 4 & 4 & 4 \\
\hline & GH115 & 2 & 2 & 2 \\
\hline & GH27 & 2 & 3 & 4 \\
\hline & GH29 & 1 & 0 & 1 \\
\hline & GH30 & 2 & 2 & 2 \\
\hline & GH35 & 3 & 3 & 4 \\
\hline & GH36 & 1 & 1 & 1 \\
\hline & GH39 & 1 & 1 & 1 \\
\hline & GH43 & 25 & 21 & 24 \\
\hline & GH51 & 0 & 0 & 1 \\
\hline & GH53 & 1 & 1 & 1 \\
\hline & GH67 & 1 & 1 & 1 \\
\hline & GH93 & 3 & 3 & 2 \\
\hline \multirow{9}{*}{ Pectin } & CE12 & 4 & 2 & 5 \\
\hline & CE8 & 4 & 3 & 4 \\
\hline & GH105 & 5 & 4 & 6 \\
\hline & GH28 & 7 & 9 & 10 \\
\hline & GH78 & 2 & 5 & 4 \\
\hline & PL1 & 11 & 12 & 17 \\
\hline & PL3 & 11 & 8 & 12 \\
\hline & PL4 & 4 & 2 & 4 \\
\hline & PL9 & 2 & 2 & 2 \\
\hline Cutin & CE5 & 5 & 4 & 7 \\
\hline Total number & & 194 & 184 & 223 \\
\hline
\end{tabular}

\subsection{Secondary Metabolite Gene Clusters}

Phytotoxic SMs are crucial weapons that phytopathogenic fungi use to invade target plants, and many are made from polyketides, non-ribosomal peptides, terpenes and alkaloids [47]. Compared with the SMs mentioned above, beta-lactones are rarely found in plant pathogens. However, with improved biochemical knowledge and bioinformatic predictions, new beta-lactones with novel functions and related biosynthetic gene clusters are being identified in fungi [48,49]. Herein, AntiSMASH 5.1.2 (fungi view) was used to identify SM BGCs in the genomes of $C$. cassiicola YN49, CC01 and CCP, and all putative SM BGCs are listed in Supplementary Materials File S1: Table S5. As shown in Table 3, YN49 and CCP both have 57 SM BGCs, while CC01 has 62. All three strains share a similar number of BGCs of most types of SM, including NRPSs, PKSs (type I and III), and indole and terpene BGCs, but PKS/NRPS, PKS/indole and beta-lactone BGCs did differ somewhat between the target strains (Table 3). CC01 has 10 PKS/NRPS BGCs, nine more than YN49 and six more than CCP. There is a single beta-lactone BGC located in both YN49 and $\mathrm{CCP}$ genomes, but none in the CC01 genome. YN49 is the only strain possessing a single PKS/indole BGC (Table 3). 
Table 3. Secondary metabolite biosynthetic gene clusters in C. cassiicola YN49, CC01 and CCP.

\begin{tabular}{cccc}
\hline SM Cluster Types & YN49 & CC01 & CCP \\
\hline NRPS & 16 & 15 & 15 \\
PKS (Type I) & 26 & 25 & 26 \\
PKS (Type III) & 1 & 1 & 1 \\
PKS/NRPS & 1 & 9 & 4 \\
PKS/Indole & 1 & 0 & 0 \\
NRPS/Indole & 0 & 1 & 0 \\
Indole & 1 & 1 & 1 \\
Terpene & 10 & 10 & 9 \\
Beta-lactone & 1 & 0 & 1 \\
Total & 57 & 62 & 57 \\
\hline
\end{tabular}

3.9. Phylogenomic Analysis of NRPS, PKS and PKS/NRPS Genes, and Domain Structure Analysis

In order to determine differences between the secondary metabolomes of $C$. cassiicola YN49, CC01 and CCP, we analysed the phylogenomic relationships of the NRPS, PKS, and PKS/NRPS BGCs identified in the three strains, based on the sequence of A and KS domains, which are relatively conserved in NRPSs and PKSs [50,51]. The phylogenomic relationships of A and KS domains indicated that most NRPSs and PKSs are conserved in these three strains, with many small clades containing three KS or A domains from three different strains (Figures 7 and 8). Most NRPSs and PKSs in the clades share an identical or similar domain structure, but some have distinct structures that differ from those of the other two strains, such as CCP-26.1KS (Figure 7) and CCP-10.1 2 3-1A (Figure 8). Compared with NRPSs and PKSs, PKS/NRPS BGCs displayed larger differences in these three strains. Although YN49 has one PKS/NRPS gene cluster containing one PKS gene and one NRPS gene, there is no PKS/NRPS gene in the YN49 genome. CC01 and CCP have six and two PKS/NRPS genes, respectively.

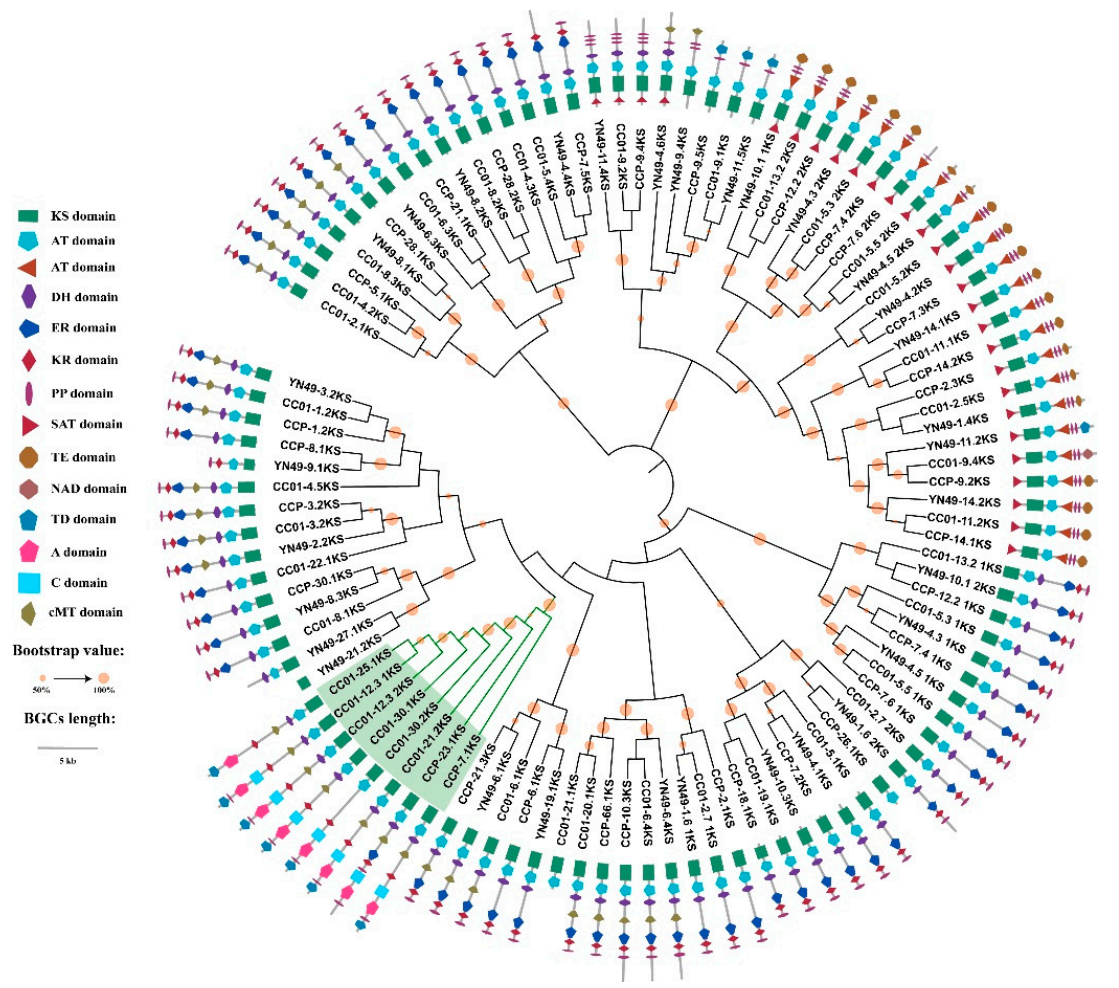

Figure 7. Phylogenetic and structure domain analyses of PKSs and PKS/NRPSs from C. cassiicola YN49, CC01 and CCP based on KS domain sequences. The PKS and PKS/NRPS domains were determined based on antiSMASH analysis. The ML tree was generated using MEGA 6 with the WAG model. Bootstrap support greater than $50 \%$ is shown on the branches. KS domain sequences used in this analysis are listed in Supplementary Materials File S5. 


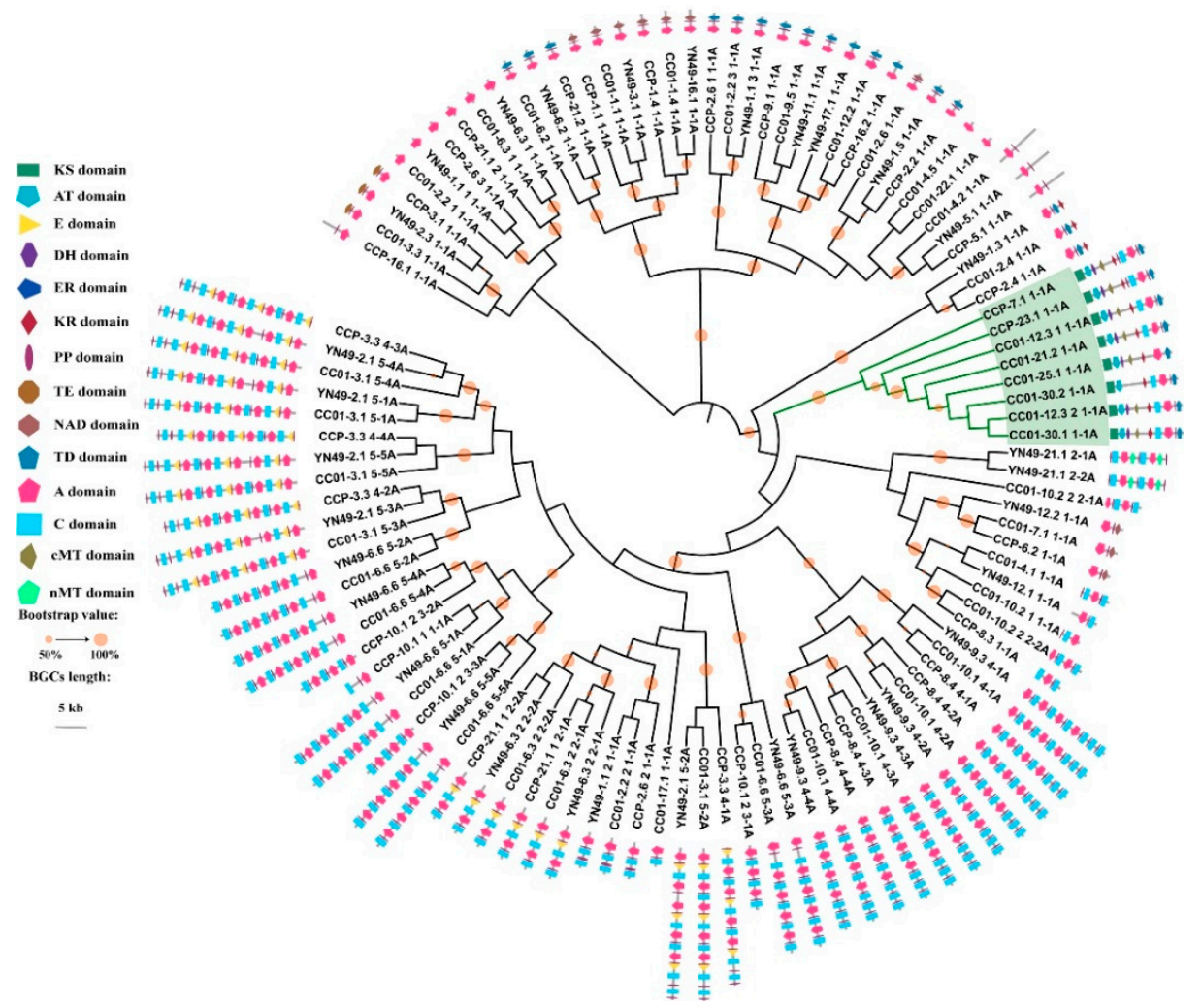

Figure 8. Phylogenetic and structural domain analysis of NRPSs and PKS/NRPSs from C. cassiicola YN49, CC01 and CCP based on A domain sequences. NRPSs and PKS/NRPSs domains were determined based on antiSMASH analysis. The ML tree was generated using MEGA 6 with the WAG model. Bootstrap support greater than $50 \%$ is shown on the branches. A domain sequences used in this analysis are listed in Supplementary Materials File S6.

\subsection{Synteny Analysis of PKS/NRPS Gene Clusters}

Our results showed that a number of PKS/NRPS clusters differ significantly between C. cassiicola YN49, CC01 and CCP (Table 3). Additionally, phylogenomic relationship analysis indicated that the PKS/NRPS genes shared high homology, and could be clustered into one clade based on the sequences of the A or KS domains (Figures 7 and 8). An intact SM BGC contains genes involved in product modification, transport, and transcription regulation, but not backbone synthesis genes whose enzymatic products produce a core metabolite [52]. To analyse the differences between PKS/NRPS clusters in target $C$. cassiicola strains, synteny of the PKS/NRPS clusters was analysed. Among the seven tested clusters, only three (CC01-21.1, CC01-25.1 and CC01-30.1) displayed good synteny. CCP-23.1, CC0130.2 and CC01-30.1 share some synteny, but CC01-12.3 and CCP-7.1 have almost no synteny with other analysed clusters (Figure 9). These results indicate large differences among the PKS/NRPS gene clusters in target $C$. cassiicola strains, which suggests that secondary metabolism may vary between C. cassiicola strains.



Figure 9. Synteny analysis of PKS/NRPS gene clusters in C. cassiicola CC01 and CCP. 


\section{Discussion}

C. cassiicola strains have been isolated from different plants with various life styles, including endophyte, saprophyte, and many necrotrophic pathogens [16,53-55]. Rubber tree CLF disease, caused by C. cassiicola, is a devastating leaf disease affecting rubber plantations in many countries in Asia and Africa, and it also threatens rubber production in China $[14,16,56]$. C. cassiicola isolates show high genetic diversity, and virulence profiles vary significantly between rubber tree cultivars [14]. Based on the amino acid sequence of the phytotoxin cassiicolin, C. cassiicola is clustered into the following seven types: Cas1-6 and Cas0. Cas2 isolates have only been found in China [15]. Except cassiicolin, little is known about the pathogenesis and associated pathogenic factors of C. cassiicola. Although 41 C. cassiicola genome assemblies are available in the NCBI database (https:/ / www.ncbi. nlm.nih.gov/genome/browse/\#!/ eukaryotes/31373/ accessed on 13 October 2020), most assemblies are not annotated, and are composed of thousands of contigs. CCP is the only annotated assembly, but it also contains hundreds of contigs [16]. In the present study, we determined two high-quality gapless genome sequences, acquired by single-molecule real-time sequencing, of two C. cassiicola strains isolated from rubber trees in China with different virulence, including one Cas 2 isolate. To decipher the genomic basis underlying the pathogenesis of CLF disease, we performed a comparative analysis of genomic data between Chinese strains and the highly virulent Philippine strain CCP.

Utilisation of host-based nutrition is critical for fungal parasitism, and gene families can contract or expand to adapt to distinct host-based nutrients [57]. For plant pathogenetic fungi, advantageous substitutions that enhance the capacity to infect hosts or adapt to new environments are likely to be rapidly fixed in the population [58]. Rubber trees are traditionally planted between $15^{\circ} \mathrm{N}$ and $10^{\circ} \mathrm{S}$, but China has 1.13 million hectares of rubber plantations between $18^{\circ} \mathrm{N}$ and $24^{\circ} \mathrm{N}$. Due to the higher latitude, cold weather is the most serious threat to rubber plantations in China. Thus, cold-resistant rubber clones have been developed and are widely cultivated in Chinese rubber tree plantations [59,60]. Different rubber tree cultivars result in different $C$. cassiicola CFL strains, including Cas 2 type isolates that infect pepper, cucumber and papaya worldwide, but infect rubber trees only in China. The virulence profiles of $C$. cassiicola vary significantly depending on rubber tree cultivars, and also display geographical specialisation $[14,56]$. There are the following two hypotheses explaining host and geographical specialisation of $C$. cassiicola: the coevolution of isolates with different rubber cultivars, and host switching from other plants. Based on our results, the Chinese Cas2 isolate CC01 appears to have diverged phylogenetically from CCP approximately 6.95 (5.29-9.18) million years ago (MYA), and the Chinese Cas5 isolate YN49 diverged 9.81 (7.64-12.82) MYA (Figure 2). Since rubber trees have only been grown in China for less than 100 years, CC01 and YN49 have presumably transferred from other host plants to rubber trees. We also found that the most expanded and contracted gene families in the genomes of the two Chinese C. cassiicola CFL strains and the Philippine strain are related to metabolic pathways (Figure 3 and Supplementary Materials, Table S4), and a large proportion of positively selected genes, which reflect the evolutionary pressure imposed by natural selection, in these three strains are metabolism-related (Figure 4 and Additional File 2: Table S6), including genes involved in carbohydrate metabolism and secondary metabolism. The diversity of metabolism-related genes allows $C$. cassiicola to adapt to different rubber cultivars, and this may lead to differences in pathogenesis and/or pathogenic factors, as YN49 and CC01 showed different virulence (Figure 1).

Plant pathogenic fungi can secrete a series of proteins that are deployed to the hostpathogen interface during infection, including enzymes interacting with plant substrates (CAZymes, peptidases and lipases), together with proteins of unknown function [61]. Necrotrophic and hemibiotrophic plant pathogenic fungi usually secrete a larger number of enzymes that are more important for host invasion than biotrophs [62,63]. Our results showed that all three tested C. cassiicola strains possess a large number of secreted proteincoding genes in their genomes. In agreement with expanded and contracted gene families results, the number of secreted protein-coding genes differed between all three tested 
C. cassiicola strains. The Cas1 isolate (CCP) has more secreted protein-encoding genes than the Cas2 isolate (CC01) and the Cas5 isolate (YN49), consistent with previous reports [16] and phenotype results (Figure 1).

CAZymes are important for carbon acquisition and metabolism in fungi, and CWDEs are used by phytopathogenic fungi as powerful weapons to penetrate and degrade the plant cell wall [64]. The Cas2 isolate (CC01) and the Cas5 isolate (YN49) were found to contain fewer CWDEs than the Cas1 isolate (CCP) in the present study, especially the Cas2 isolate (Table 2). The most obvious difference was the number of pectin- and cutin-degrading enzymes, and GH5, which is related to cellulose degradation (Table 2). Pectinolytic enzymes are important in pathogenesis as potential virulence factors, especially in phytopathogens affecting dicots, since the pectin content of the cell wall $(30 \%)$ is much higher than that of monocots $(10 \%)[65,66]$. Other pathogenetic fungi affecting rubber trees, such as Colletotrichum spp., also secrete pectin lyases to invade rubber leaves [67,68]. CCP encodes many more secreted pectin lyases than YN49 and CC01, such as GH28, PL1, and three other families, and CC01 possesses the fewest pectinolytic enzyme-encoding genes. This suggests that pectin degradation ability varies between different $C$. cassiicola strains, and Cas1 isolates might degrade pectin components more effectively than Cas2 and Cas5 isolates, this could partially explain the pathogenicity difference between different C. cassiicola strains.

Rubber tree leaves are covered with a thick, waxy cuticle, and the thickness is related to pathogen resistance $[18,69]$. The cuticle consists a matrix of mid-chain hydroxy and/or epoxy C16 and/or C18 fatty acid monomers and waxes, including numerous very-longchain fatty acids (VLCFAs; C20-C40). Both the cuticle and the waxes cover the surface of leaves to prevent water loss and invasion of pathogens [70]. To breach these hydrophobic layers, many phytopathogenic fungi secrete cutinases and lipases in the early stages of infection, as demonstrated for Valsa mali, Blumeria graminis and F. graminearum [45,47,71]. One CCP strain was found to encode 11 putative cutinases, more than are present in hemibiotrophs, aprotrophs and ectomycorrhizal fungi [16]. Herein, we analysed the distribution of secreted cutinases between different cassicolin toxin classes, and the results indicated that Cas1 isolates possess more secreted cutinase-encoding genes than Cas2 and Cas5 isolates, with Cas2 isolates containing the fewest. The trend in the number of secreted lipase-encoding genes differed from the results of cutinase analysis; CCP encodes fewer secreted lipase genes than both YN49 and CC01. In order further evaluate the lipid degradation ability, we combined the results of secreted lipase and PHI analyses, and found that CCP possesses more pathogenicity-relevant lipases than CC01, but fewer than YN49 (Figure 3). Thus, Cas1 isolates (CCP) and Cas5 isolates (YN49) appear to encode more putative cuticle and wax degradation enzymes than Cas2 isolates (CC01), and this might be one of the reasons explain why CC01 showed less virulence than YN49 (Figure 1).

Phytotoxins (PTs) are largely represented by low-molecular-weight SMs that disrupt vital activities of plant cells and/or cause death at concentrations below $10 \mathrm{mM}$ [72]. Cassiicolin is the only phytotoxin of $C$. cassiicola characterised to date, and the cassiicolin gene has only been detected in $47 \%$ of isolates. Based on the presence of the cassiicolin toxin and its amino acid sequence, $C$. cassiicola strains are divided into seven categories (Cas1-6 and Cas0) [14]. Since C. cassiicola shows high genetic diversity and little correlation between genetic clades and the traits of strains, many studies have attempted to connect cassiicolin types with pathogenicity and geographical locations. Most such studies have been carried out on rubber trees, and the results vary between different cultivars. The only thing in common is that Cas1 isolates, especially CCP strains, are more virulent toward some specific cultivars $[8,14,73]$.

In our previous study, we analysed the pathogenicity of three C. cassiicola isolates of three different toxin classes (Cas2, Cas5 and Cas0), which are the dominant populations in Chinese rubber plantations, toward four different rubber tree cultivars. All three isolates showed differences in pathogenicity toward the four clones, and there were no obvious trends [74]. In the present work, YN49 showed stronger virulence than CC01 toward 
Hevea brasiliensis clone Reyan7-33-97 (Figure 1). Comparative genomic results showed that $\mathrm{CCP}$ contains many more CWDEs than YN49 and CC01, and CC01 has the fewest such enzymes. Thus, we speculate that the cassicolin toxin is not the only pathogenic factor affecting the virulence of $C$. cassiicola toward rubber trees, and secreted CWDEs also play an important role during pathogenesis, particularly in the early stages of infection. Secreted CWDEs are potent weapons used by C. cassiicola to breach the cell wall barrier, and assist the release of cassicolin and other pathogenic factors. Thus, a thick cuticle and wax layer covering rubber tree leaves, and other enhanced cell wall structures, may effectively prevent the invasion of $C$. cassiicola strains lacking CWDEs, but may be unable to block the penetration of C. cassiicola strains containing numerous CWDEs. Since the resistance of rubber tree leaves and CWDEs of different $C$. cassiicola strains remain unclear, the results of pathogenicity tests on the CFL strains were somewhat difficult to interpret. This may partially explain why different rubber tree clones show differences in susceptibility to CLF disease. For example, GT1 is resistant in Africa but highly sensitive in Thailand [8].

Numerous C. cassiicola strains do not encode the cassicolin toxin, and some can still cause CFL disease in rubber trees in many areas, including China, India and Thailand [8,62]. Similarly, serval Cas0 isolates were found to infect cucumber [15]. These findings indicate that $C$. cassiicola contains other pathogenic factors in addition to the cassicolin toxin. Phytopathogenic fungi, especially filamentous fungi, usually contain dozens of SM BGCs encoding a diverse array of small molecules that function as phytotoxins, antibiotics and pigments [24,52]. Herein, we identified $~ 60$ SM BGCs in three different $C$. cassiicola strains, many more than the average for phytopathogenic fungi, consistent with previous studies, indicating that $C$. cassiicola possesses the genomic basis for the synthesis of various SMs [16,75]. Based on the genomes of 66 different Aspergillus fumigatus strains, Lind et al. (2017) summarised five general types of variation in SM BGCs within a fungal species, and revealed diversity and discontinuity in the distributions of SM BGCs, including between strains sharing high levels of synteny [52]. Although the total number of SM BGCs is similar in the three analysed C. cassiicola strains, they have significant differences in the number of genes encoding beta-lactone, PKS/indole and NRPS/indole SM BGCs, and especially PKS/NRPS BGCs (Table 3). PKS/indole and NRPS/indole BGCs are only present in YN49 and CC01, and beta-lactone BGCs are not present in CC01, indicating whole-gene cluster polymorphisms in C. cassiicola for SM BGCs. Further phylogenomic and domain structure analyses showed that although most PKSs and NRPSs could be clustered into one clade with high bootstrap value support, some parts had distinct domain structures, such as the PKS of the CCP-7.5 cluster and the YN49-11.2 cluster, and the NRPS of the CCP-10.1 cluster (Figures 7 and 8). This is consistent with single nucleotide polymorphisms (SNPs) and short indel polymorphisms. All the PKS/NRPSs could be clustered into one clade based on A or KS domain sequences, suggesting that PKS/NRPSs are relatively highly conserved between C. cassiicola strains (Figures 7 and 8). However, synteny analysis of clusters containing PKS/NRPSs gave diverse results; only three clusters showed synteny, while the rest shared almost no synteny (Figure 9). This indicates gene content polymorphisms in C. cassiicola SM BGCs, even between clusters with similar core genes. C. cassiicola SM BGC polymorphisms likely correlate with differences in SMs between strains, and this may be one of the reasons why C. cassiicola displays complex pathotypic diversity.

\section{Conclusions}

This study determined high-quality whole-genome sequences of two Chinese isolates (YN49 and CC01) of C. cassiicola that cause CLF disease of rubber trees. Comparative genomics of gene families in these two stains and the virulent CCP strain from the Philippines showed that $C$. cassiicola strains with different geographic origins have experienced different selective pressures, resulting in differences in metabolism-related gene families. Secreted protein analysis indicates that the number of secreted CWDEs is correlated with pathogenesis, and the structural resistance of rubber tree leaves may also influence the 
pathogenicity of CFL strains. C. cassiicola strains encode numerous SM BGCs, and there is significant diversity and discontinuity in the distribution of SM BGCs between C. cassiicola strains. This implies SM polymorphisms between C. cassiicola strains, which may play an important role in pathogenic progress. These findings form the basis for further experimental studies on the pathogenesis of rubber tree CLF disease.

Supplementary Materials: The following are available online at https: / www.mdpi.com/article / 10.3390/jof7060485/s1, File S1: Table S1: BUSCO analysis of C. cassiicola isolates YN49 and CC01 scaffolds assembly; Table S2: RNA statistics of C. cassiicola isolates YN49 and CC01; Table S3: Repeative sequence statistic of C. cassiicola isolates YN49 and CC01; Table S4: Gene annotation statistic of C. cassiicola isolates YN49 and CC01; Table S5: SM Clusters coordinates of C. cassiicola isolates YN49, CC01 and CCP scaffolds assembly. File S2: Table S1: KEGG distribution of expanded gene families of C. cassiicola YN49, CC01 and CCP; Table S2: KEGG distribution of contracted gene families of C. cassiicola YN49, CC01 and CCP; Table S3: KEGG distribution of positive selection genes of C. cassiicola YN49, CC01 and CCP; Table S4: Expanded gene families of C. cassiicola YN49, CC01 and CCP; Table S5: Contracted gene families of C. cassiicola YN49, CC01 and CCP; Table S6: Positive selection genes of C. cassiicola YN49, CC01 and CCP. File S3: Table S1: Secreted Cazymes of C. cassiicola YN49, CC01 and CCP; Table S2: Secreted protease of C. cassiicola YN49, CC01 and CCP; Table S3: Secreted lipases of C. cassiicola YN49, CC01 and CCP. File S4: Table S1: Genes relevant to fungal pathogenicity of $C$. cassiicola YN49; Table S2: Genes relevant to fungal pathogenicity of $C$. cassiicola CC01; Table S3: Genes relevant to fungal pathogenicity of C. cassiicola CCP. File S5: Sequences of KS domains used in this study. File S6: Sequences of A domains used in this study. File S7: C. cassiicola starins and their Cas gene sequences used in this study. Figure S1: Phylogenic analysis of C. cassiicola starins with Cas gene sequence; Figure S2: KEGG pathway enrichment of contracted gene families.

Author Contributions: Y.Y. and P.X. performed all the bioinformatics analyses of the data presented in this paper. B.L. and X.L. performed experiments and provided materials. T.S., J.C., Y.C. and C.L. analysed the data. Y.Y. and G.H. wrote the manuscript. All authors participated in figure and table preparation and revision of the final version of the manuscript. All authors have read and agreed to the published version of the manuscript.

Funding: This work was supported in part by grants National Key R\&D Program of China (2019YFD1000500), the Central Public-interest Scientific Institution Basal Research Fund for Chinese Academy of Tropical Agricultural Sciences (No. 1630042020014). The funders had no role in study design, data collection and analysis, decision to publish, or preparation of the manuscript.

Institutional Review Board Statement: Not applicable.

Informed Consent Statement: Informed consent was obtained from all subjects involved in the study.

Data Availability Statement: The whole-genome sequencing datasets from this study have been submitted to the BioProject database of the National Center for Biotechnology Information (NCBI) (https: / / www.ncbi.nlm.nih.gov/ accessed on 13 October 2020) under accession number PRJNA687613 and PRJNA687612. All sequencing raw data were uploaded to the NCBI Sequence Read Archive (http:/ / www.ncbi.nlm.nih.gov/sra accessed on 13 October 2020) database under the GenBank accession numbers SRR13318044 and SRR13316927.

Acknowledgments: The authors thank Diggers Company (Wuhan, China) for assistance with bioinformatics software and analysis.

Conflicts of Interest: The authors declare no conflict of interest.

\section{References}

1. Schoch, C.; Crous, P.; Groenewald, J.; Boehm, E.; Burgess, T.; de Gruyter, J.; de Hoog, G.; Dixon, L.; Grube, M.; Gueidan, C.; et al. A class-wide phylogenetic assessment of Dothideomycetes. Stud. Mycol. 2009, 64, 1-15. [CrossRef]

2. Yan, X.; Yu, C.; Fu, X.A.; Bao, F.; Du, D.; Wang, C.; Wang, N.; Wang, S.; Shi, Z.; Zhou, G.; et al. CARD 9 mutation linked to Corynespora cassiicola infection in a Chinese patient. Br. J. Dermatol. 2016, 174, 176-179. [CrossRef]

3. Zhao, D.-L.; Shao, C.-L.; Gan, L.-S.; Wang, M.; Wang, C.-Y. Chromone Derivatives from a Sponge-Derived Strain of the Fungus Corynespora cassiicola. J. Nat. Prod. 2015, 78, 286-293. [CrossRef]

4. Carris, L.M.; Glawe, D.A.; Gray, L.E. Isolation of the Soybean Pathogens Corynespora cassiicola and Phialophora gregata from Cysts of Heterodera glycines in Illinois. Mycologia 1986, 78, 503. [CrossRef] 
5. Deighton, F.C. XXXVIII. Preliminary list of fungi and diseases of plants in Sierra Leone. Bull. Misc. Inf. 1936, 7, $397-424$.

6. Liyanage, A.S.; Jayasinghe, C.; Liyanage, N.I.S.; Jayaratne, A.H.R. Corynespora leaf spot disease of rubber (Hevea brasiliensis) a new record. J. Rubber Res. Inst. Sri Lanka 1986, 65, 47-50.

7. Dixon, L.J.; Schlub, R.L.; Pernezny, K.; Datnoff, L.E. Host Specialization and Phylogenetic Diversity of Corynespora cassiicola. Phytopathology 2009, 99, 1015-1027. [CrossRef]

8. Tran, D.M.; Clément-Demange, A.; Déon, M.; Garcia, D.; Le Guen, V.; Clement-Vidal, A.; Soumahoro, M.; Masson, A.; Label, P.; Le, M.T.; et al. Genetic determinism of sensitivity to Corynespora cassiicola Exudates in rubber tree (Hevea brasiliensis). PLoS ONE 2016, 11, e0162807. [CrossRef]

9. Jinji, P.; Xin, Z.; Yangxian, Q.; Yixian, X.; Huiqiang, Z.; He, Z. First record of Corynespora leaf fall disease of Hevea rubber tree in China. Australas. Plant Dis. Notes 2007, 2, 35-36. [CrossRef]

10. Li, Z.; Fox, J.M. Mapping rubber tree growth in mainland Southeast Asia using time-series MODIS $250 \mathrm{~m}$ NDVI and statistical data. Appl. Geogr. 2012, 32, 420-443. [CrossRef]

11. Chen, B.; Xiao, X.; Wu, Z.; Yun, T.; Kou, W.; Ye, H.; Lin, Q.; Doughty, R.; Dong, J.; Ma, J.; et al. Identifying establishment year and pre-conversion land cover of rubber plantations on Hainan Island, China using landsat data during 1987-2015. Remote Sens. 2018, 10, 1240. [CrossRef]

12. Yang, X.; Blagodatsky, S.; Liu, F.; Beckschäfer, P.; Xu, J.; Cadisch, G. Rubber tree allometry, biomass partitioning and carbon stocks in mountainous landscapes of sub-tropical China. For. Ecol. Manag. 2017, 404, 84-99. [CrossRef]

13. Déon, M.; Bourré, Y.; Gimenez, S.; Berger, A.; Bieysse, D.; de Lamotte, F.; Poncet, J.; Roussel, V.; Bonnot, F.; Oliver, G.; et al. Characterization of a cassiicolin-encoding gene from Corynespora cassiicola, pathogen of rubber tree (Hevea brasiliensis). Plant Sci. 2012, 185-186, 227-237. [CrossRef]

14. Déon, M.; Fumanal, B.; Gimenez, S.; Bieysse, D.; Oliveira, R.R.; Shuib, S.S.; Breton, F.; Elumalai, S.; Vida, J.B.; Seguin, M.; et al. Diversity of the cassiicolin gene in Corynespora cassiicola and relation with the pathogenicity in Hevea brasiliensis. Fungal Biol. 2014, 118, 32-47. [CrossRef] [PubMed]

15. Wu, J.; Xie, X.; Shi, Y.; Chai, A.; Wang, Q.; Li, B. Variation of cassiicolin genes among Chinese isolates of Corynespora cassiicola. J. Microbiol. 2018, 56, 634-647. [CrossRef] [PubMed]

16. Lopez, D.; Ribeiro, S.; Label, P.; Fumanal, B.; Venisse, J.-S.; Kohler, A.; De Oliveira, R.R.; LaButti, K.; Lipzen, A.; Lail, K.; et al. Genome-wide analysis of corynespora cassiicola leaf fall disease putative effectors. Front. Microbiol. 2018, 9, 276. [CrossRef] [PubMed]

17. Cosgrove, D.J. Growth of the plant cell wall. Nat. Rev. Mol. Cell Biol. 2005, 6, 850-861. [CrossRef] [PubMed]

18. Xinchun, Z.; Xiangmin, L. Ultrastructural studies on the interaction of rubber tree with oidium heveae. Chin. J. Trop. Crop. 2010, $31,2250-2254$.

19. Kubicek, C.P.; Starr, T.L.; Glass, N.L. Plant cell wall-degrading enzymes and their secretion in plant-pathogenic fungi. Annu. Rev. Phytopathol. 2014, 52, 427-451. [CrossRef] [PubMed]

20. Zhi-Heng, L.; Ye, Q.I.; Xin-Yang, H.; Hong, Y.; Yue, H.; Rui, Z. Conditions and activity analysis of cell wall degrading enzymes produced from Corynespora cassiicola of brown spot of cucumber. China Veg. 2011, 8, 76-80.

21. Breton, F.; Sanier, C.; D'Auzac, J. Role of cassiicolin, a host-selective toxin, in pathogenicity of Corynespora cassiicola, causal agent of a leaf fall disease of Hevea. Gastroenterology 2000, 120, A173-A174.

22. Vining, L.C. Functions of secondary metabolites. Annu. Rev. Microbiol. 1990, 44, 395-427. [CrossRef]

23. Pusztahelyi, T.; Holb, I.J. Pã ${ }^{3}$ CsiI. Secondary metabolites in fungus-plant interactions. Front. Plant Sci. 2015, 6, 573. [CrossRef]

24. Keller, N.P. Translating biosynthetic gene clusters into fungal armor and weaponry. Nat. Chem. Biol. 2015, 11, 671-677. [CrossRef]

25. Koren, S.; Walenz, B.P.; Berlin, K.; Miller, J.R.; Bergman, N.H.; Phillippy, A.M. Canu: Scalable and accurate long-read assembly via adaptivek-mer weighting and repeat separation. Genome Res. 2017, 27, 722-736. [CrossRef]

26. Walker, B.J.; Abeel, T.; Shea, T.; Priest, M.; Abouelliel, A.; Sakthikumar, S.; Cuomo, C.A.; Zeng, Q.; Wortman, J.; Young, S.K.; et al. Pilon: An integrated tool for comprehensive microbial variant detection and genome assembly improvement. PLoS ONE 2014, 9, e112963. [CrossRef] [PubMed]

27. Simão, F.A.; Waterhouse, R.M.; Ioannidis, P.; Kriventseva, E.V.; Zdobnov, E.M. BUSCO: Assessing genome assembly and annotation completeness with single-copy orthologs. Bioinformatics 2015, 31, 3210-3212. [CrossRef]

28. Birney, E. Using GeneWise in the drosophila annotation experiment. Genome Res. 2000, 10, 547-548. [CrossRef]

29. Li, L.; Stoeckert, C.J.; Roos, D.S. OrthoMCL: Identification of ortholog groups for eukaryotic genomes. Genome Res. 2003, 13, 2178-2189. [CrossRef] [PubMed]

30. Stamatakis, A. RAxML-VI-HPC: Maximum likelihood-based phylogenetic analyses with thousands of taxa and mixed models. Bioinformatics 2006, 22, 2688-2690. [CrossRef]

31. Li, H. Minimap2: Pairwise alignment for nucleotide sequences. Bioinformatics 2018, 34, 3094-3100. [CrossRef]

32. De Bie, T.; Cristianini, N.; DeMuth, J.P.; Hahn, M.W. CAFE: A computational tool for the study of gene family evolution. Bioinformatics 2006, 22, 1269-1271. [CrossRef]

33. Yang, Z. PAML 4: Phylogenetic analysis by maximum likelihood. Mol. Biol. Evol. 2007, 24, 1586-1591. [CrossRef] [PubMed]

34. Bedell, J.A.; Korf, I.; Gish, W. MaskerAid: A performance enhancement to RepeatMasker. Bioinformatics 2000, 16, 1040-1041. [CrossRef] [PubMed] 
35. Xu, Z.; Wang, H. LTR_FINDER: An efficient tool for the prediction of full-length LTR retrotransposons. Nucleic Acids Res. 2007, 35, W265-W268. [CrossRef] [PubMed]

36. Lombard, V.; Ramulu, H.G.; Drula, E.; Coutinho, P.M.; Henrissat, B. The carbohydrate-active enzymes database (CAZy) in 2013. Nucleic Acids Res. 2014, 42, D490-D495. [CrossRef] [PubMed]

37. Fischer, M. The Lipase Engineering Database: A navigation and analysis tool for protein families. Nucleic Acids Res. 2003, 31, 319-321. [CrossRef] [PubMed]

38. Rawlings, N.D.; Barrett, A.J.; Thomas, P.D.; Huang, X.; Bateman, A.; Finn, R.D. The MEROPS database of proteolytic enzymes, their substrates and inhibitors in 2017 and a comparison with peptidases in the PANTHER database. Nucleic Acids Res. 2018, 46, D624-D632. [CrossRef]

39. Blin, K.; Shaw, S.; Steinke, K.; Villebro, R.; Ziemert, N.; Lee, S.Y.; Medema, M.H.; Weber, T. antiSMASH 5.0: Updates to the secondary metabolite genome mining pipeline. Nucleic Acids Res. 2019, 47, W81-W87. [CrossRef]

40. Tamura, K.; Stecher, G.; Peterson, D.; Filipski, A.; Kumar, S. MEGA6: Molecular evolutionary genetics analysis Version 6.0. Mol. Biol. Evol. 2013, 30, 2725-2729. [CrossRef]

41. Hahn, M.W.; De Bie, T.; Stajich, J.; Nguyen, C.; Cristianini, N. Estimating the tempo and mode of gene family evolution from comparative genomic data. Genome Res. 2005, 15, 1153-1160. [CrossRef] [PubMed]

42. Powell, A.J.; Conant, G.C.; E Brown, D.; Carbone, I.; A Dean, R. Altered patterns of gene duplication and differential gene gain and loss in fungal pathogens. BMC Genom. 2008, 9, 147. [CrossRef] [PubMed]

43. Rao, S.; Nandineni, M.R. Genome sequencing and comparative genomics reveal a repertoire of putative pathogenicity genes in chilli anthracnose fungus Colletotrichum truncatum. PLOS ONE 2017, 12, e0183567.

44. Urban, M.; Pant, R.; Raghunath, A.; Irvine, A.G.; Pedro, H.; Hammond-Kosack, K.E. The Pathogen-Host Interactions database (PHI-base): Additions and future developments. Nucleic Acids Res. 2015, 43, D645-D655. [CrossRef]

45. Blümke, A.; Falter, C.; Herrfurth, C.; Sode, B.; Bode, R.; Schäfer, W.; Feussner, I.; Voigt, C.A. Secreted fungal effector lipase releases free fatty acids to inhibit innate immunity-related callose formation during wheat head infection. Plant Physiol. 2014, 165, 346-358. [CrossRef]

46. Chang, H.-X.; Yendrek, C.R.; Caetano-Anolles, G.; Hartman, G.L. Erratum to: Genomic characterization of plant cell wall degrading enzymes and in silico analysis of xylanases and polygalacturonases of Fusarium virguliforme. BMC Microbiol. 2017, 17, 110. [CrossRef]

47. Yin, Z.; Liu, H.; Li, Z.; Ke, X.; Dou, D.; Gao, X.; Song, N.; Dai, Q.; Wu, Y.; Xu, J.; et al. Genome sequence of Valsa canker pathogens uncovers a potential adaptation of colonization of woody bark. New Phytol. 2015, 208, 1202-1216. [CrossRef]

48. Robinson, S.L.; Christenson, J.K.; Wackett, L.P. Biosynthesis and chemical diversity of $\beta$-lactone natural products. Nat. Prod. Rep. 2018, 36, 458-475. [CrossRef]

49. Tang, X.-X.; Yan, X.; Fu, W.-H.; Yi, L.-Q.; Tang, B.-W.; Yu, L.-B.; Fang, M.-J.; Wu, Z.; Qiu, Y.-K. New $\beta$-Lactone with tea pathogenic fungus inhibitory effect from marine-derived fungus MCCC3A00957. J. Agric. Food Chem. 2019, 67, 2877-2885. [CrossRef]

50. Bushley, K.E.; Turgeon, B.G. Phylogenomics reveals subfamilies of fungal nonribosomal peptide synthetases and their evolutionary relationships. BMC Evol. Biol. 2010, 10, 26. [CrossRef]

51. Kroken, S.; Glass, N.L.; Taylor, J.W.; Yoder, O.C.; Turgeon, B.G. Phylogenomic analysis of type I polyketide synthase genes in pathogenic and saprobic ascomycetes. Proc. Natl. Acad. Sci. USA 2003, 100, 15670-15675. [CrossRef]

52. Lind, A.; Wisecaver, J.H.; Lameiras, C.; Wiemann, P.; Palmer, J.M.; Keller, N.P.; Rodrigues, F.; Goldman, G.H.; Rokas, A. Drivers of genetic diversity in secondary metabolic gene clusters within a fungal species. PLoS Biol. 2017, 15, e2003583. [CrossRef]

53. SuryanarayananT, T.S.; Murali, T.S.; Thirunavukkarasu, N.; Rajulu, M.B.G.; Venkatesan, G.; Sukumar, R. Endophytic fungal communities in woody perennials of three tropical forest types of the Western Ghats, southern India. Biodivers. Conserv. 2011, 20, 913-928. [CrossRef]

54. Gond, S.K.; Verma, V.C.; Kumar, A.; Kumar, V.; Kharwar, R.N. Study of endophytic fungal community from different parts of Aegle marmelos Correae (Rutaceae) from Varanasi (India). World J. Microbiol. Biotechnol. 2007, 23, 1371-1375. [CrossRef]

55. Cai, L.; Ji, K.-F.; Hyde, K.D. Variation between freshwater and terrestrial fungal communities on decaying bamboo culms. Antonie van Leeuwenhoek 2006, 89, 293-301. [CrossRef] [PubMed]

56. Qi, Y.-X.; Zhang, X.; Pu, J.-J.; Liu, X.-M.; Lu, Y.; Zhang, H.; Zhang, H.-Q.; Lv, Y.-C.; Xie, Y.-X. Morphological and molecular analysis of genetic variability within isolates of Corynespora cassiicola from different hosts. Eur. J. Plant Pathol. 2011, 130, 83-95. [CrossRef]

57. Zhang, W.; Zhang, X.; Li, K.; Wang, C.; Cai, L.; Zhuang, W.; Xiang, M.; Liu, X. Introgression and gene family contraction drive the evolution of lifestyle and host shifts of hypocrealean fungi. Mycology 2018, 9, 176-188. [CrossRef] [PubMed]

58. Aguileta, G.; Lengellé, J.; Chiapello, H.; Giraud, T.; Viaud, M.; Fournier, E.; Rodolphe, F.; Marthey, S.; Ducasse, A.; Gendrault, A.; et al. Genes under positive selection in a model plant pathogenic fungus, Botrytis. Infect. Genet. Evol. 2012, 12, 987-996. [CrossRef]

59. Deng, X.; Wang, J.; Li, Y.; Wu, S.; Yang, S.; Chao, J.; Chen, Y.; Zhang, S.; Shi, M.; Tian, W. Comparative transcriptome analysis reveals phytohormone signalings, heat shock module and ROS scavenger mediate the cold-tolerance of rubber tree. Sci. Rep. 2018, 8, 4931. [CrossRef]

60. Cheng, H.; Chen, X.; Fang, J.; An, Z.; Hu, Y.; Huang, H. Comparative transcriptome analysis reveals an early gene expression profile that contributes to cold resistance in Hevea brasiliensis (the Para rubber tree). Tree Physiol. 2018, 38, 1409-1423. [CrossRef] 
61. González-Fernández, R.; Prats, E.; Jorrín-Novo, J.V. Proteomics of Plant Pathogenic Fungi. J. Biomed. Biotechnol. 2010, $2010,1-36$. [CrossRef]

62. Miller, M.E.; Zhang, Y.; Omidvar, V.; Sperschneider, J.; Schwessinger, B.; Raley, C.; Palmer, J.M.; Garnica, D.; Upadhyaya, N.; Rathjen, J.; et al. De Novo Assembly and Phasing of Dikaryotic Genomes from Two Isolates of Puccinia coronata f. sp. avenae, the Causal Agent of Oat Crown Rust. mBio 2018, 9. [CrossRef]

63. Zhao, Z.; Liu, H.; Wang, C.; Xu, J.-R. Comparative analysis of fungal genomes reveals different plant cell wall degrading capacity in fungi. BMC Genom. 2013, 14, 274. [CrossRef]

64. Quoc, N.B.; Chau, N.N.B. The Role of Cell Wall Degrading Enzymes in Pathogenesis of Magnaporthe oryzae. Curr. Protein Pept. Sci. 2017, 18, 1019-1034. [CrossRef]

65. Lara-Márquez, A.; Oyama, K.; Zavala-Páramo, M.G.; Villa-Rivera, M.G.; Conejo-Saucedo, U.; Cano-Camacho, H. Evolutionary analysis of pectin lyases of the genus colletotrichum. J. Mol. Evol. 2017, 85, 120-136. [CrossRef] [PubMed]

66. Gan, P.; Ikeda, K.; Irieda, H.; Narusaka, M.; O'Connell, R.J.; Narusaka, Y.; Takano, Y.; Kubo, Y.; Shirasu, K. Comparative genomic and transcriptomic analyses reveal the hemibiotrophic stage shift of Colletotrichum fungi. New Phytol. 2013, 197, 1236-1249. [CrossRef]

67. Liu, X.; Li, B.; Cai, J.; Zheng, X.; Feng, Y.; Huang, G. Colletotrichum Species Causing Anthracnose of Rubber Trees in China. Sci. Rep. 2018, 8, 1-14. [CrossRef]

68. Fernando, T.; Jayasinghe, C.; Wijesundera, R. Cell wall degrading enzyme secretion by Colletotrichum acutatum the causative fungus of secondary leaf fall of Hevea brasiliensis. Mycol. Res. 2001, 105, 195-201. [CrossRef]

69. Barthe, P.; Pujade-Renaud, V.; Breton, F.; Gargani, D.; Thai, R.; Roumestand, C.; de Lamotte, F. Structural Analysis of Cassiicolin, a Host-selective Protein Toxin from Corynespora cassiicola. J. Mol. Biol. 2007, 367, 89-101. [CrossRef]

70. Aragón, W.; Reina-Pinto, J.J.; Serrano, M. The intimate talk between plants and microorganisms at the leaf surface. J. Exp. Bot. 2017, 68, 5339-5350. [CrossRef]

71. Feng, J.; Wang, F.; Liu, G.; Greenshields, D.; Shen, W.; Kaminskyj, S.; Hughes, G.R.; Peng, Y.; Selvaraj, G.; Zou, J.; et al. Analysis of a Blumeria graminis-Secreted Lipase Reveals the Importance of Host Epicuticular Wax Components for Fungal Adhesion and Development. Mol. Plant Microbe Interact. 2009, 22, 1601-1610. [CrossRef]

72. Berestetskiy, A.O. A review of fungal phytotoxins: From basic studies to practical use. Appl. Biochem. Microbiol. 2008, 44, 453-465. [CrossRef]

73. Ribeiro, S.; Tran, D.M.; Déon, M.; Clément-Demange, A.; Garcia, D.; Soumahoro, M.; Masson, A.; Pujade-Renaud, V. Gene deletion of Corynespora cassiicola cassiicolin Cas1 suppresses virulence in the rubber tree. Fungal Genet. Biol. 2019, 129, 101-114. [CrossRef]

74. Xianbao, L.; Boxun, L.I.; Shan, C.; Guixiu, H. Diversity and pathogenicity of the cassiicolin gene in corynespora cassiicola of rubber tree in China. Chin. J. Trop. Crops 2016, 37, 1969-1973.

75. Gao, S.; Zeng, R.; Xu, L.; Song, Z.; Gao, P.; Dai, F. Genome sequence and spore germination-associated transcriptome analysis of Corynespora cassiicola from cucumber. BMC Microbiol. 2020, 20, 1-20. [CrossRef] 